com mucopolissacaridose podem apresentar elevada prevalência de atraso na erupção dentária, alteração da morfologia dentária e oclusal, cárie dentária e gengivorragia. Têm-se verificado atrasos significativos no diagnóstico correto desta patologia, impedindo uma intervenção atempada, o que poderia evitar a progressão da doença e prevenir a ocorrência de danos irreversíveis. Assim, pretendemos, com esta exposição, a divulgação desta entidade e a disponibilização de informação relativa aos cuidados de saúde a que esta população tem direito.

http://doi.org/10.24873/j.rpemd.2019.12.468

\section{\#005 Parésia Facial Periférica Após Bloqueio do Nervo Alveolar Inferior}

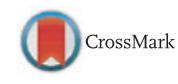

Maria Rodrigues*, Ana Boyé de Sousa, Diana Breda, João Mendes de Abreu, José Pedro Figueiredo

Centro Hospitalar e Universitário de Coimbra, Faculdade de Medicina da Universidade de Coimbra

Introdução: O bloqueio do nervo alveolar inferior é uma técnica de anestesia regional amplamente utilizada em procedimentos estomatológicos. O caso clínico descreve o desenvolvimento imediato de uma parésia facial periférica, após a realização de bloqueio do nervo alveolar inferior num contexto de extracção dentária. Descrição do caso clínico: Uma mulher saudável de 26 anos com história de pericoronarites de repetição do terceiro molar mandibular esquerdo apresentou-se numa consulta para a extracção do mesmo. Foi realizado um bloqueio do nervo alveolar inferior através da injecção de uma solução de cloridrato de mepivacaína $3 \%$ num volume total de $1.7 \mathrm{~mL}$ com uma agulha de $38 \mathrm{~mm}$ em aspiração. A anestesia foi eficaz, tendo a extracção dentária decorrido sem complicações. Imediatamente após o procedimento a doente queixou-se de fraqueza muscular da hemiface esquerda. Observou-se incapacidade em realizar oclusão da fenda palpebral esquerda, obliteração da prega nasolabial e das pregas frontais à esquerda e desvio da comissura labial para a direita. A doente foi mantida em observação, tendo-se verificado uma resolução progressiva ao longo de 3 horas. Foi feita uma reavaliação no dia seguinte e após 2 semanas, tendo-se verificado uma normalização completa da mímica facial. Discussão e conclusões: O desenvolvimento de parésia facial periférica após a realização de um bloqueio do nervo alveolar inferior é uma complicação rara, que se pode verificar imediata ou tardiamente. A parésia imediata resulta do envolvimento do nervo facial no tecido parotídeo. Uma injecção demasiado profunda pode levar à inoculação de anestésico no lobo profundo da parótida, com disseminação da solução anestésica para os ramos do nervo facial. Nestes casos é expectável a recuperação da mímica facial decorrido o tempo de acção da solução anestésica, como se verificou no caso descrito. Ainda assim, é essencial realizar o seguimento do doente até que ocorra recuperação total. A persistência de parésia ou um desenvolvimento tardio da mesma podem estar associados a outros mecanismos de lesão do nervo facial, merecendo uma investigação cuidada e tratamento de acordo com as causas.
O objectivo da descrição deste caso é alertar para a possibilidade desta intercorrência rara num procedimento habitual, e reforçar a importância de tranquilizar o doente, explicando a evolução natural do quadro e verificando a resolução do mesmo.

http://doi.org/10.24873/j.rpemd.2019.12.469

\#006 Lesões radiopacas - um desafio diagnóstico: a propósito de um caso clínico

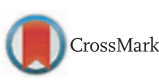

Andreia Gonçalves Silva*, Lídia Gomes, Diogo Branco, Sílvio Fortes, Mário Gouveia, Júlio Rodrigues

Hospital de Braga

Introdução: As lesões radiopacas dos maxilares surgem frequentemente nos exames radiológicos solicitados na prática clínica. Estas lesões podem apresentar diversas localizações, formas, dimensões e etiologias. As displasias cemento-ósseas constituem um conjunto de lesões fibro-ósseas raras, benignas, auto-limitadas, que afetam mais mulheres de raça negra, por volta da quarta e quinta década de vida. A origem destas lesões não é clara, no entanto, existe um consenso geral de que se originam a partir do ligamento periodontal. As osteoscleroses idiopáticas definem-se como áreas de esclerose, de etiologia desconhecida, com maior incidência em mulheres de raça negra, entre a terceira e quarta década de vida. São aceites como variantes anatómicas, não estando relacionadas com processos inflamatórios, neoplásicos, displásicos ou patologias sistémicas. Na cavidade oral, localizam-se com maior frequência na região posterior da mandíbula. Descrição do caso clínico: Doente do sexo feminino, 30 anos de idade, raça caucasiana, sem antecedentes pessoais de relevo, medicação habitual ou alergias. Referenciada para a consulta de Estomatologia do Hospital de Braga por apresentar uma lesão radiopaca no quarto quadrante. A doente apresentava-se sem qualquer tipo de queixas. Ao exame objetivo não se verificava qualquer alteração de relevo da cavidade oral. A ortopantomografia realizada demonstrava uma imagem radiopaca, no quarto quadrante, com halo radiolucente, em estreita relação com a região periapical do dente 43. Adjacente ao dente 4.8, verificava-se ainda uma lesão radiopaca homogénea com limites bem definidos. Discussão e conclusões: O diagnóstico definitivo das displasias cemento-ósseas e osteoscleroses idiopáticas requer apenas a integração de aspectos clínicos e radiológicos. As displasias cemento-ósseas podem ser confundidas com lesões periapicais, tais como abcessos, lesões quísticas e alguns tumores odontogénicos. No entanto, para além de não haver sintomatologia associada, estas lesões relacionam-se com um dente viável, não restaurado e com o ligamento periodontal integro. As osteoscleroses idiopáticas apresentam um vasto conjunto de diagnósticos diferenciais. Contudo, também não apresentam sintomatologia associada nem qualquer evolução das suas características ao longo do tempo. Ambas as entidades patológicas não requerem tratamento e por isso, o erro diagnóstico pode conduzir à realização de procedimentos invasivos supérfluos e dos seus riscos inerentes.

http://doi.org/10.24873/j.rpemd.2019.12.470 